\title{
Age and education related preferences for pictograms concerning driving-impairing medicines
}

\author{
Susana P. Monteiro ${ }^{1,2,3}$, Julia C.M. van Weert ${ }^{4 *}$, Johan J. de Gier ${ }^{1,2}$ and Liset van Dijk ${ }^{3}$ \\ ${ }^{1}$ Department of Pharmacotherapy and Pharmaceutical Care, University of Groningen, Groningen, the Netherlands \\ ${ }^{2}$ Driving Under the Influence of Drugs, Alcohol and Medicines (DRUID) project, the Netherlands \\ ${ }^{3}$ NIVEL, Netherlands Institute for Health Services Research, Utrecht, the Netherlands \\ ${ }^{4}$ Amsterdam School of Communication Research / ASCoR, Department of Communication Science, University of Amsterdam, Amsterdam, the Netherlands
}

\begin{abstract}
Purpose: Pictograms can increase public awareness about driving-impairing effects of medicines. However, pictograms that are not clear will negatively affect the comprehension of the message. Older and low educated adults are particularly vulnerable to misunderstandings. Comprehension is expected to be influenced by preference for the type of pictograph, but little is known about the preference of pictograms among drivers of different age groups and education levels. This study aims to investigate older and lower educated adults' preference for a pictogram (triangle model pictogram versus rating model pictogram) related to the influence of taking driving-impairing medicines on driving fitness.
\end{abstract}

Methods: Interviews among 270 drivers visiting a pharmacy were conducted. Participants were asked about their preference for the best pictogram expressing a warning message and expressing levels of impairment. A comparison between a pictogram with a more complex design (rating model) and an already implemented one (triangle model) was made.

Results: $74.4 \%$ of the participants preferred the rating model to express warning messages and $82.6 \%$ preferred this model to express levels of impairment. However, older and low educated participants were more likely to prefer the triangle model over the more complex rating model. Age was the strongest predictor influencing participants' preference for pictograms to express a warning message and levels of impairment. Young participants (18-39 years old) with high education level had the highest preference for the rating model, whereas older participants ( $\geq 60$ years old) with low education level showed the lowest preference for this pictogram system.

Conclusion: Age and education level are sensitive factors to be considered when designing a pictogram. In order to be equally well understood by older and low educated adults, pictograms should have a simple design and make use of familiar objects.

\section{Introduction}

Older patients (over 65 years) consume about one third of all prescribed medicines [1]. A substantial part of these patients use psychoactive substances, mainly benzodiazepines and opioid analgesics. These medicines act on the central nervous system and, thus, are likely to impair fitness to drive. The driving-impairing effects of such substances vary greatly, and several (pharmaco)epidemiological studies have shown an increased traffic accident risk associated with its use [2-4]. It has also been reported that older drivers lack awareness of the effects of psychoactive medicines on driving fitness [5]. The same holds true for adults with low education level. A recent study showed that patients with low education level had less knowledge about the influence of driving-impairing medicines than patients with high education level [6]. Raising older and lower educated adult's awareness of medicines and psychomotor fitness to drive safely is positively associated with driving self-regulating behaviours $[7,8]$.

As an attempt to increase public awareness and knowledge of the driving-impairing effects of certain medicines $[9,10]$ pictograms related to the influence of driving-impairing medicines on driving fitness were developed and implemented in some European countries, like the Netherlands, Denmark, Finland, Norway and, more recently, France and Spain [11]. The pictogram developed in France (triangle model) was considered to be a step forward, as it encompassed a 3-tier labelling system with a side-text (Figure 1). This system allowed making a distinction between different levels of impairment (category 1,2 or 3 ) of a medicine on driving fitness, but it failed to give an overall perspective of all the existent levels of risks in one single pictogram. To overcome this gap, a new pictogram (rating model) was designed within the European project DRUID - Driving Under the Influence of Drugs, alcohol and medicines [12], aiming at providing users of driving-impairing medicines with a straightforward and clear grading system (Figure 1). In comparison, the triangle model pictogram appears to have a simpler design than the rating model pictogram. Complex pictograms might be more difficult to understand, indicating that the rating model pictogram could be harder to understand. However, a recent study comparing these two pictograms found that the rating model was on average better understood than the triangle model [13].

When designing a pictogram it is important to recognize and take into consideration the preferences of the target population so that

Correspondence to: Julia C.M. van Weert, Amsterdam School of Communication Research / ASCoR, University of Amsterdam, P.O. Box 15791, 1001 NG Amsterdam, The Netherlands, Tel.: +31 20 5252091; E-mail: j.c.m.vanweert@uva.nl

Key words: aging, DRUID project, health communication, low education, pictorial aids, risk perception

Received: June 12, 2017; Accepted: July 04, 2017; Published: July 06, 2017 


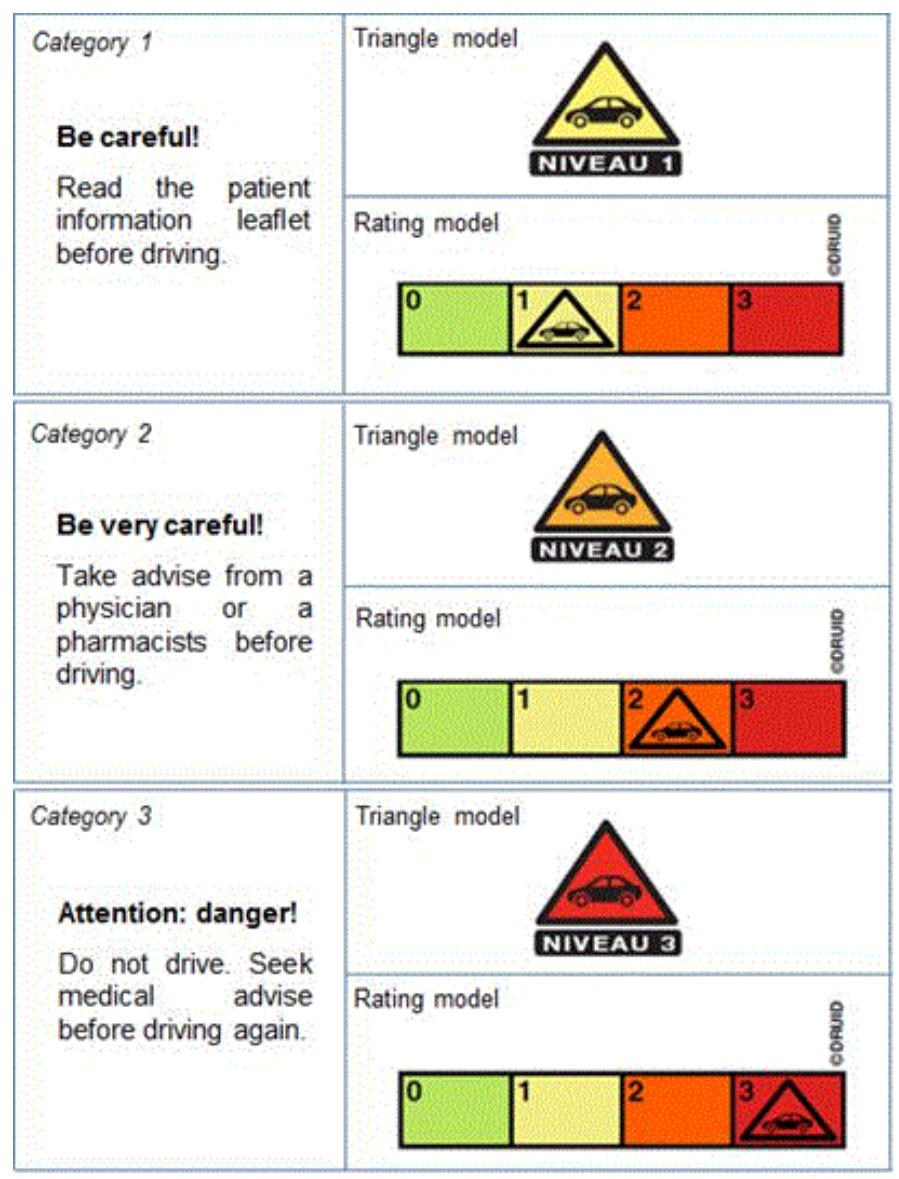

Figure 1. Representation of how participants were shown the pictograms that allowed them to answer the questions: "which pictogram better expresses the warning message?" and "which pictogram better express different levels of impairment?". The warning message for each category is presented on the left-side. For each category of impairment, participants were shown the correspondent triangle and rating pictogram at the same time.

the pictogram catches the target group's attention. According to the Elaboration Likelihood Model (ELM) of persuasion [14], an individual is more likely to find motivation and ability to centrally process information when the message contains relevant elements $[14,15]$. In other words, information that is tailored to individual preferences and interests is processed more deeply [16], which is expected to improve comprehension and recall of information $[14,17,18]$.

Despite some advantages associated to its use, especially in conveying warning messages $[9,10,19-25]$, pictograms are figures representing ideas and concepts which may not always be clear to all, affecting the comprehension of the message [26,27]. Older and low educated adults are recognized to be particularly vulnerable to misunderstandings and often times have difficulties interpreting the message being conveyed [26-32]. Regardless of the growing number of pictograms related to driving-impairing medicines that have been developed in the past few years, to the best of our knowledge no published studies investigated the preference for driving-impairing pictograms by older adults or people with low education levels. In order to fill this existent gap, this research aims to investigate older and lower educated adults' preference for a pictogram related to drivingimpairing medicines (triangle model pictogram versus rating model pictogram).

\section{Methods}

\section{Study design}

This study among patients with a driving license visiting a pharmacy was part of a larger study existing of an experiment with a 2 (rating model pictogram versus triangle model pictogram) by 3 (categories of impairment: minor driving risk versus moderate driving risk versus severe driving risk) between-subjects design, followed by an interview. Ninety participants were interviewed per pictogram category (category 1, 2 or 3), in total 270 participants. As illustrated in Figure 1 , participants were shown at the same time the same category of the triangle and rating model pictograms with the side-text message next to it. A pre-test was conducted in a small sample $(n=20)$ of patients visiting a community pharmacy, not part of the actual study. The pretest served to test the clarity of the questions asked and to estimate the time needed to complete the interview. No adjustments were necessary after the pre-test.

The study was conducted in four selected Dutch community pharmacies located in Groningen, the Netherlands. Inclusion criteria were 1) actively participating in traffic with motorized vehicles; 2) aged 18 years or older and 3) being able to speak and read Dutch. The interview was carried out in Dutch and participants were interviewed in the waiting area of the pharmacy by a research associate. The interview consisted of four distinct parts: 1) socio-demographic characteristics of the participant, 2) general knowledge about medicines and driving, 3) specific questions about the pictogram, and 4) comparison between 2 pictograms. The current study only focuses on the first and the fourth part of the interview. For parts 2 and 3, participants were randomly exposed to only one out of three possible pictograms (triangle model, rating model with side-text and rating model without side-text) to investigate the pictograms' effectiveness in understanding the message. The results have been published elsewhere [13]. In total, 270 participants were needed for this study. Data-collection stopped once this number was reached (see results for response rates).

In the Netherlands, no approval from the Medical Ethic Committee is needed for studies like this, since it only included an interview about interpretation of pictograms in a general context (not related to medication received) after explicitly asking for patients' informed consent. Moreover, all healthcare professionals and participants involved were adequately informed about the nature of the study, participated voluntarily and anonymously.

\section{Measurements}

The pictogram preference (triangle or rating model pictograms) was investigated by asking participants "which pictogram better expresses the warning message?" and "which pictogram better expresses different levels of impairment?". For both questions, participants were shown at the same time the triangle and the rating model corresponding to one pictogram category (category 1,2 or 3 ) and had to select the pictogram of their choice, i.e., only one pictogram could be of their preference (Figure 1). Despite their association $\left(\mathrm{X}^{2}(1,270)=121.8 ; \mathrm{p}<0.001\right)$, the two items were used as two separate dependent variables, as we believed that, in case participants do have different preferences with regard to the warning level and the level of impairment, this would be helpful to draw conclusions about the best pictogram. Additionally, it allowed us to investigate who were the participants that changed their preference depending on the pictogram message. 
Age and education level were the main independent variables. To assess age differences in the outcomes, the following age intervals were used: younger participants (18-39 years), middle aged participants (4059 years), and older participants (60 years and older) [33,34]. Education level included low (not completed primary school, completed primary school, lower professional education), intermediate (moderate professional education) and high (higher educational or university degree) levels.

Gender (male, female), pictogram risk category (1,2 or 3 ) and pictogram shown at the start of the interview (triangle model, rating model with or without side-text) were used as control variables.

\section{Statistical analysis}

Descriptive analysis was conducted on participants' characteristics, such as age, education level and gender. ANOVA and chi-square tests of independence were used, where appropriate, to investigate differences in age, education level and gender between participants exposed to different conditions, i.e., pictogram systems (triangle model, rating model with side-text, rating model without side-text).

Chi-square tests of independence were conducted to investigate differences in participants' preference for one pictogram to express a warning message and to express levels of impairment. Univariate analysis was used to investigate whether there were age and education level differences in the preference for one pictogram system (triangle or rating model pictograms).

Multiple logistic regression analysis was used to assess the influence of age and education level on participants' preference for the pictogram in expressing a warning message (model 1 ) and on levels of impairment (model 2). These models were controlled for gender, pictogram's category, and pictogram shown at the start of the interview. A p-value of $<0.05$ was considered to be statistically significant.

\section{Results}

A total of 360 persons were approached; 32 (of whom $75 \%$ females) did not possess a driving license and were excluded. Of the remaining 328 persons, 58 ( $62.1 \%$ females) did not want to take part in the study for several reasons: no time (44.8\%), no interest (29.3\%), not feeling fit due to illness (12.1\%), and other reasons (13.8\%). The net response of the study was $82.3 \%$; 270 out of 328 eligible persons were included in this study.

The total study population was equally distributed in terms of gender ( $\mathrm{n}=137 ; 50.7 \%$ males). The mean age of the participants was 48 years-old ( $\mathrm{sd}=14.4$; range $20-78$ years; $27.4 \%(\mathrm{n}=74)$ " $18-39$ "; $46.7 \%$ $(\mathrm{n}=126)$ " $40-59$ " and $25.9 \%(\mathrm{n}=70)$ "69-79"). Regarding education level, 20.0\% $(\mathrm{n}=54)$ of the participants had low education, $34.4 \%$ $(n=93)$ had intermediate level and $45.6 \%(n=123)$ had high education. No significant differences were found between age $(F(2,270)=0.242$, $p=0.785)$, education level $\left(X^{2}(4,270)=1.278, p=0.865\right)$, and gender $\left.X^{2}(2,270)=1.452, p=0.484\right)$ between conditions.

The percentage of participants preferring the rating model (201 out of $270 ; 74.4 \%$ ) to express a warning message was significantly higher than those preferring the triangle model ( 69 out of $270 ; 25.6 \%), X^{2}(1,270)$ $=12.6, p<0.001$. Statistically significant differences between preference for one pictogram and age were found, $F(2,267)=6.39, p=0.002$; older adults ( $>60$ years old) were more likely to prefer the triangle model pictogram over the rating model. This group significantly differed from middle aged participants $(p=0.035)$ and younger participants $(p=$ 0.002) which have shown preference for the rating model pictogram to express a warning message. Statistically significant differences were found, $F(2,267)=4.67, p=0.01$, between pictogram preference and education level; participants with lower education were more likely to prefer the triangle model whereas participants with intermediate and high education levels preferred the rating model pictogram to express a warning message.

Results from the multiple logistic regression (Table 1) confirmed the previous results and showed that age was the strongest predictor influencing preference for pictograms expressing warning messages. The independent variables explained $17.6 \%$ of the variance for pictogram preference in explaining warning messages.

As for the best pictogram expressing levels of impairment, $82.6 \%$ (223 out of 270) of the participants preferred the rating model pictogram. Results indicated statistically significant differences between pictogram preference and age, $F(2,267)=14.21, p<0.001$, and between education level and the condition, $F(2,267)=7.62, p=0.001$. According to the multiple regression model (Table 1), age was the strongest predictor influencing preference. Participants between 20-39 years-old and 40-59 were, respectively, 11 and almost 4 times more likely to prefer the rating model pictogram over the triangle one when compared to participants between 60-79 years-old (reference group). Educational level also had an impact: participants with intermediate and high level of education were, respectively, 2 and 3 times more likely to prefer the rating model to express different levels of impairment than those with low education level. The independent variables explained $26.7 \%$ of the variance.

Participants preferred the rating model to express both a warning message and levels of impairment, but the percentage decreased among elderly and participants with lower educational level.

Combining the influence of age and education level in participants' preference for the rating model pictogram (Figure 2), it can be depicted that participants in the category "younger (18-39 years old) with high education level" ( $n=46)$ had the highest preference for the rating model pictogram in expressing a warning message, whereas participants in the category "older ( $>60$ years old) with low education level" $(n=10)$ showed the lowest preference for this pictogram system. Similar results were found regarding the preference for the rating model system in expressing levels of impairment (Figure 2). No interaction effects between age and education level were found, $F(4,270)=0.81, p=0.52$.

Some participants shifted their preference between pictograms (Figure 2). From those who preferred the triangle model to express a warning message, $39.0 \%$ (27 out of 69 ) considered that the rating model pictogram was best to express levels of impairment. Those who preferred the rating model to express a warning message, $2.5 \%$ (5 out of 201) considered that the triangle model pictogram was best to express levels of impairment. Table 2 displays the characteristics (age and education level) of the participants who did and who did not changed their preference for one pictogram depending on the message being conveyed.

\section{Discussion}

This research investigated participants' preference for one pictogram related to driving-impairing medicines and its risk in traffic. Both pictograms conveyed the same message but differed in the design. The rating model pictogram was more complex than the triangle model, requiring more complex cognitive aspects to process and integrate the information. Even so, the rating model pictogram was preferred over the triangle model pictogram to express both a warning message and 

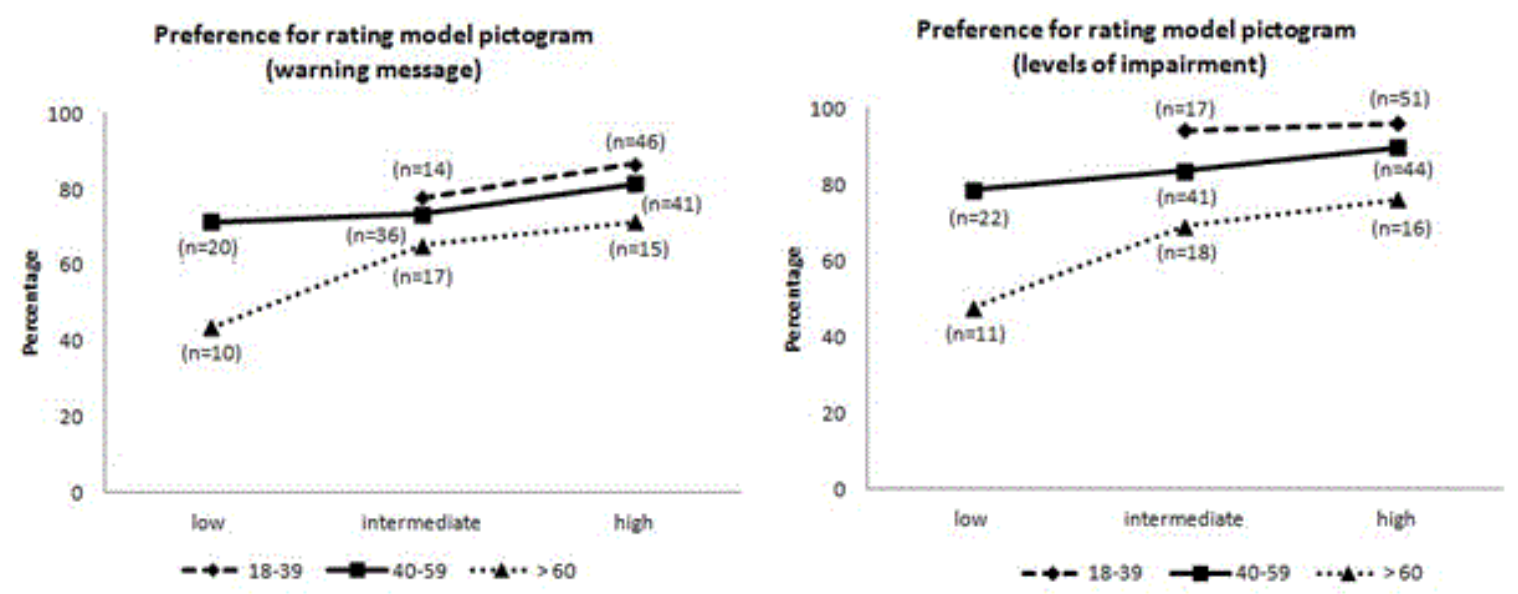

Note: category young with low education level was left out due to the low number ( $n=3 ; 10096$ ).

Figure 2. Preferences for the rating model to express a warning message and levels of impairment depending on participants' age and education level.

Table 1. Factors influencing participants' preference for one pictogram in expressing warning messages and levels of impairment: multiple logistic regression analysis. a $0=$ Triangle model; 1=Rating model. "P-value $<0.05$ considered to be statistically significant.

\begin{tabular}{|c|c|c|c|c|c|c|}
\hline \multirow{3}{*}{ Independent variables } & \multicolumn{3}{|c|}{$\begin{array}{l}\text { Preference for pictogram model in expressing a warning message } \\
\qquad(\mathrm{N}=270)^{\mathrm{a}}\end{array}$} & \multicolumn{3}{|c|}{$\begin{array}{l}\text { Preference for pictogram model in expressing levels of impairment } \\
\qquad(\mathrm{N}=270)^{\mathrm{a}}\end{array}$} \\
\hline & \multirow{2}{*}{$\begin{array}{c}\text { Odds-Ratio } \\
\text { Ratio }\end{array}$} & \multicolumn{2}{|c|}{$95 \% \mathrm{CI}$ for OR } & \multirow{2}{*}{$\begin{array}{c}\text { Odds-Ratio } \\
\text { Ratio }\end{array}$} & \multicolumn{2}{|c|}{$95 \% \mathrm{CI}$ for OR } \\
\hline & & lower & upper & & lower & upper \\
\hline \multicolumn{7}{|c|}{ Age Categories (60-79 used as reference) } \\
\hline $20-39$ & $3.11^{*}$ & 1.27 & 7.63 & $11.26^{*}$ & 2.94 & 43.12 \\
\hline $40-59$ & $2.30^{*}$ & 1.15 & 4.62 & $3.72^{*}$ & 1.7 & 8.15 \\
\hline \multicolumn{7}{|c|}{ Education level (low level as reference) } \\
\hline Intermediate & 1.35 & 0.63 & 2.89 & 1.94 & 0.82 & 4.56 \\
\hline High & 2.08 & 0.93 & 4.62 & $2.81^{*}$ & 1.12 & 7.06 \\
\hline \multicolumn{7}{|c|}{ Control variables } \\
\hline Gender $(0=$ female; $1=$ male $)$ & 1.08 & 0.58 & 2.00 & 1.33 & 0.63 & 2.79 \\
\hline \multicolumn{7}{|c|}{ Pictogram category (category 3 as reference) } \\
\hline Category 1 & 1.91 & 0.95 & 3.88 & $2.44^{*}$ & 1.02 & 5.83 \\
\hline Category 2 & $2.35^{*}$ & 1.12 & 4.94 & 1.71 & 0.72 & 4.05 \\
\hline \multicolumn{7}{|c|}{ Pictogram shown at the start of the interview (triangle model as reference) } \\
\hline Rating model with side text & $2.83^{*}$ & 1.39 & 5.77 & $2.30^{*}$ & 1.01 & 5.20 \\
\hline Rating model without side text & $2.99^{*}$ & 1.46 & 6.12 & $4.16^{*}$ & 1.68 & 10.31 \\
\hline Nagelkerke R2 & \multicolumn{3}{|c|}{$0.176(17.6 \%)$} & \multicolumn{3}{|c|}{$0.267(26.7 \%)$} \\
\hline p-value (model) & \multicolumn{3}{|c|}{$<0.001^{*}$} & \multicolumn{3}{|c|}{$<0.001^{*}$} \\
\hline
\end{tabular}

Table 2. Participants' preferred pictogram to express warning messages and levels of impairment.

\begin{tabular}{|c|c|c|c|c|c|}
\hline & \multicolumn{5}{|c|}{ Preferred pictogram to express a warning message $\rightarrow$ Preferred pictogram to express levels of impairment } \\
\hline & Triangle $\mathrm{n}(\%)$ & Rating n (\%) & Rating n (\%) & Triangle $\mathrm{n}(\%)$ & P-value \\
\hline \multicolumn{6}{|c|}{ Age categories } \\
\hline $20-39(\mathrm{~N}=74)$ & $3(4.1)$ & $63(85.1)$ & $8(10.8)$ & 0 & \\
\hline $40-59(\mathrm{~N}=126)$ & $16(12.7)$ & $93(73.8)$ & $14(11.1)$ & $3(2.4)$ & $<0.001$ \\
\hline $60-79(\mathrm{~N}=70)$ & $23(32.9)$ & $40(57.1)$ & $5(7.1)$ & $2(2.9)$ & \\
\hline \multicolumn{6}{|c|}{ Education level } \\
\hline Low $(\mathrm{N}=54)$ & $18(33.3)$ & $33(61.1)$ & $3(5.6)$ & 0 & \\
\hline Intermediate $(\mathrm{N}=93)$ & $13(14.0)$ & $63(67.7)$ & $13(14.0)$ & $4(4.3)$ & $<0.001$ \\
\hline $\operatorname{High}(\mathrm{N}=123)$ & $11(8.9)$ & $100(81.3)$ & $11(8.9)$ & $1(0.8)$ & \\
\hline
\end{tabular}

levels of impairment in all age groups and education levels. However, older and low educated participants demonstrated to have less preference for the more complex rating model and they were also less likely to change their opinion towards this more complicated model. This study confirmed that both age and education level are sensitive aspects to be considered when designing a pictogram to be equally well understood by older adults and those who have a low education level.
Adults over 65 years old represent a substantial and increasing proportion of drivers [35]. This group is also known to chronically take several medications, some of them recognized to impair driving fitness [35]. Considering that this group of the general population is not always fully aware of the risks posed by their medication intake $[1,35]$, it is important to find strategies that will help these patients, not only to be fully aware of the risks of taking driving-impairing 
medicines, but also to be able to discuss these issues with a health care provider.

Assuming that preference can help understanding, since the use of familiar objects or messages can foster information processes (Elaboration Likelihood Model of persuasion [14]), hypothetically it could be argued that a pictogram that is preferred has a higher chance of being well understood and, therefore, effective in conveying messages. Results from this study indicate that the rating model pictogram was preferred over the triangle model and, therefore, can be seen as an effective tool to communicate the risk of driving under the influence of driving-impairing medicines to patients throughout all ages and education levels. Additionally, in another study, the warning message conveyed by this pictogram model was better understood than the triangle model [13].

However, the proportion of participants above 60 years old and with low education preferring the pictogram model to express warning messages and levels of impairment decreased. This indicates that the rating model pictogram seems more suitable to younger and high educated participants than to older and low educated participants. A possible explanation for this deals with the fact that the design of the rating model pictogram, though more complete than the triangle model, is more complex and, therefore, may be more difficult to understand. This result is not surprising as, nowadays, complex pictograms and signs are widespread and part of daily life routines. Those who are younger and higher educated tend to be more prone to understand and follow those instructions, making them more adjustable to unfamiliar and complex pictograms. On the other hand, older and low educated adults respond better to what they are used to [36] and are highly penalized when they are requested to interpret icons with complex messages that require more cognitive resources for interpretation [36]. Applying this to the present study, it is reasonable to assume that familiarity influenced older and low educated participants' preference for the triangle model pictogram. A stand-alone triangle (triangle model pictogram), can be more familiar than a rating scale with a triangle inside (rating mode pictogram) as it may recall caution or dangerous situations. Additionally, triangles are commonly used in traffic. Familiarity can equally explain why old and low educated participants were more reluctant to change their preference, as they were less likely to prefer a different pictogram to explain different information.

Despite the encouraging results of the rating model pictogram, which seem to be well designed and able to convey a warning message and different levels of warning risk, attention should be paid to the fact that results on another study using on the understanding of the rating pictogram showed that $35.6 \%$ (32 out of 90) of the participants were able to fully understand the meaning of the pictogram, i.e., were able to identify a traffic-related message and made a reference to the risk category [13] Worth mentioning that, in that same study, the percentage of participants who fully understood the message conveyed by the triangle model was notoriously lower $(7,8 \%, 7$ out of 90). This re-enforces the message that pictograms should, at all times, be accompanied by other information given to patients at the time of consultation, by a healthcare provider. In this way, the efficacy of the message given to the patient can be improved.

This study should be seen in the light of some limitations and strengths. The main limitation of the study deals with the fact that the population might not be representative of the general population as this study was conducted in a small convenient sample $(\mathrm{N}=270)$ in the North of the Netherlands. Nevertheless, results from this study confirm that attention should be paid to specific target groups, namely older people and those with low education level, when designing pictograms which are known to be particularly useful for these two specific target groups. Another limitation deals with the fact that participants were shown one of the pictograms prior to being asked to indicate the one of their preference. Albeit this variable had been controlled for, it could have had an impact in the preference for one pictogram. Previous research indicated that familiarization plays an important role in understanding, as discussed above. The present study is, to be best of authors' knowledge, the first one attempting to compare two pictograms related to the use of driving-impairing medicines and to investigate which one better illustrates warning messages in participants' opinion.

\section{Conclusion}

The more complex rating model pictogram was preferred over the triangle model throughout the whole population, but this preference is more emphasized among younger adults and those with high education levels. Age and education level were among the tested predictors, the ones influencing the most preference for one pictogram. Clearly, young and high educated respondents preferred the rating model, with a more complex design, whereas older adults and those with lower education levels preferred the triangle model.

Future research should evaluate the rating and triangle model pictograms among different target groups who take driving-impairing medicines and drive. If a pictogram related to driving-impairing medicines is to be implemented, specific training to healthcare providers regarding this topic should be given, as the pictogram may raise some questions from patients which need to be answered. It is equally important that health care providers are aware that older and low educated patients need special attention as they are particularly sensitive to pictograms and their understanding of the meaning of the pictograms is not always straightforward.

\section{Acknowledgment}

The authors would like to thank the research associate, René Huiskes, for conducting the interviews and to all participants enrolled in this study for their collaboration in data collection. Furthermore, we would like to thank the pharmacists who allowed us to conduct the interviews in their pharmacies.

\section{Disclosure}

The authors do not have any conflict of interest to declare.

This study, part of the DRUID project, was financed by the European Community within the framework of the EU 6th Framework Program (Contract No TREN-05-FP6TR-S07.61320-518404-DRUID). This article reflects only the authors' views. The European Community is not liable for any use that may be made of the information contained therein.

\section{References}

1. EMCDDA (2008) Substance use among older adults: a neglected problem. European Monitoring Centre for Drugs and Drug Addiction, drugs in focus.

2. Ravera S, van Rein N, de Gier JJ, de Jong-van den Berg LT (2011) Road traffic accidents and psychotropic medication use in The Netherlands: a case-control study. $\mathrm{Br}$ J Clin Pharmacol 72: 505-513. [Crossref]

3. Meesmann U, Boets S, Monteiro SP, de Gier JJ, Fierro I, et al. (2011) Main DRUID results to be communicated to different target groups (WP7). DRUID.

4. Ojaniemi KK, Lintonen TP, Impinen AO, Lillsunde PM, Ostamo AI (2009) Trends in driving under the influence of drugs: A register-based study of DUID suspects during 1977-2007. Accid Anal Prev 41: 191-196. 
5. EMCDDA (2014) European Monitoring Centre for Drugs and Drug Addiction. Drugs in focus 20 - responding to drug driving in Europe.

6. Monteiro SP, Dijk LV, Verstraete AG, Alvarez FJ, Heissing M, et al. (2012) Predictors for patient knowledge and reported behaviour regarding driving under the influence of medicines: A multi-country survey. BMC Public Health 12: 59

7. Eby DW, Molnar LJ, Shope JT, Vivoda JM, Fordyce TA (2003) Improving older driver knowledge and self-awareness through self-assessment: The driving decisions workbook. $J$ Safety Res 34: 371-381.

8. Owsley C, Stalvey BT, Phillips JM (2003) The efficacy of an educational intervention in promoting self-regulation among high-risk older drivers. Accid Anal Prev 35: 393400 .

9. Katz MG, Kripalani S, Weiss BD (2006) Use of pictorial aids in medication instructions: a review of the literature. Am J Health Syst Pharm 63: 2391-2397. [Crossref]

10. Mansoor LE, Dowse R (2004) Design and evaluation of a new pharmaceutical pictogram sequence to convey medicine usage. Ergonomics $S A$ 16: 29-41.

11. Gómez-Talegón T, Fierro I, del Rio C, Álvarez FJ (2011) Establishment of framework for classification/categorisation and labelling of medicinal drugs and driving. Results from the DRUID project. Driving under the Influence of Drugs, Alcohol and Medicines, DRUID.

12. DRUID (2014) Driving under the Influence of Drugs, Alcohol and Medicines.

13. Monteiro SP, Huiskes R, Van Dijk L, Van Weert JC, De Gier JJ (2013) How effective are pictograms in communicating risk about driving-impairing medicines? Traffic Inj Prev 14: 299-308.

14. Petty RE, Cacioppo JT (1986) The elaboration likelihood model of persuasion. In: Berkowitz L (Ed) The elaboration likelihood model of persuasion. San Diego, CA: Academic Press pp. 123-205.

15. Cacioppo JT, Petty RE, Kao CF, Rodriguez R (1986) Central and peripheral routes to persuasion: An individual difference perspective. Journal of Personality and Social Psychology 51: 1032-1043.

16. Tam KY, Ho SY (2005) Web personalization as a persuasion stretagy: An elaboration likelihood model perspective. Information System Research 16: 271-291.

17. Petty RE, Cacioppo JT (1986) Communication and persuasion: Central and peripheral routes to attitude change. New York, Springer p. 262.

18. Roberts NJ, Evans G, Blenkhorn P, Partridge MR (2010) Development of an electronic pictorial asthma action plan and its use in primary care. Patient Educ Couns 80: 141146. [Crossref]

19. Dowse R, Ehlers MS (2001) The evaluation of pharmaceutical pictograms in a lowliterate South African population. Patient Educ Couns 45: 87-99. [Crossref]

20. Dowse R, Ehlers M (2005) Medicine labels incorporating pictograms: Do they influence understanding and adherence? Patient Educ Couns 58: 63-70.

21. Houts PS, Witmer JT, Egeth HE, Loscalzo MJ, Zabora JR (2001) Using pictographs to enhance recall of spoken medical instructions II. Patient Educ Couns 43: 231-242. [Crossref]
22. Houts PS, Doak CC, Doak LG, Loscalzo MJ (2006) The role of pictures in improving health communication: A review of research on attention, comprehension, recall, and adherence. Patient Educ Couns 61:173-190.

23. Sorfleet C, Vaillancourt R, Grloves S, Dawson J (2009) Design, development and evaluation of pictographic instructions for medications used during humanitarian missions. Canadian Pharmacists Journal 142: 82-88.

24. Hill LH, Roslan MR (2004) Using visual concept mapping to communicate medication information to chronic disease patients with low health literacy. Presented at First International Conference on Concept Mapping, Spain.

25. Houts PS, Bachrach R, Witmer JT, Tringali CA, Bucher JA, et al. (1998) Using pictographs to enhance recall of spoken medical instructions. Patient Educ Couns 35: 83-88.

26. Wolf MS, Davis TC, Tilson HH, Bass PF 3rd, Parker RM (2006) Misunderstanding of prescription drug warning labels among patients with low literacy. Am J Health Syst Pharm 63: 1048-1055. [Crossref]

27. Davis TC, Wolf MS, Bass PF, Middlebrooks M, Kennen E, et al. (2006) Low literacy impairs comprehension of prescription drug warning labels. J Gen Intern Med 21: 847851. [Crossref]

28. Morrell RW, Park DC, Poon LW (1990) Effects of labeling techniques on memory and comprehension of prescription information in young and old adults. $J$ Gerontol 45 : P166-172. [Crossref]

29. Wolf MS, Davis TC, Bass PF, Curtis LM, Lindquist LA, et al. (2010) Improving prescription drug warnings to promote patient comprehension. Arch Intern Med 170: 50-56. [Crossref]

30. Davis TC, Wolf MS, Bass PF 3rd, Thompson JA, Tilson HH, et al. (2006) Literacy and misunderstanding prescription drug labels. Ann Intern Med 145: 887-894. [Crossref]

31. Wolf MS, Davis TC, Shrank W, Rapp DN, Bass PF, et al. (2007) To err is human patient misinterpretations of prescription drug label instructions. Patient Educ Couns 67: 293-300. [Crossref]

32. Knapp P, Raynor DK, Jebar AH, Price SJ (2005) Interpretation of medication pictograms by adults in the UK. Ann Pharmacother 39: 1227-1233. [Crossref]

33. Renaud B, Buda M, Lewis BD, Pujol JF (1975) Effects of 5,6-dihydroxytryptamine on tyrosine-hydroxylase activity in central catecholaminergic neurons of the rat. Biochem Pharmacol 24: 1739-1742. [Crossref]

34. Silliman RA, Troyan SL, Guadagnoli E, Kaplan SH, Greenfield S (1997) The impact of age, marital status, and physician-patient interactions on the care of older women with breast carcinoma. Cancer 80: 1326-1334.

35. Sargent-Cox KA, Windsor T, Walker J, Anstey KJ (2011) Health literacy of older drivers and the importance of health experience for self-regulation of driving behaviour. Accid Anal Prev 43: 898-905.

36. Morrow DG, Leirer VO, Andrassy JM (1996) Using icons to convey medication schedule information. Appl Ergon 27: 267-275. [Crossref]

Copyright: $\odot 2017$ Monteiro SP. This is an open-access article distributed under the terms of the Creative Commons Attribution License, which permits unrestricted use, distribution, and reproduction in any medium, provided the original author and source are credited. 